\title{
The Importance Of Marketing Segmentation
}

Gillian Martin, Kaplan University, USA

\begin{abstract}
The rationale behind marketing segmentation is to allow businesses to focus on their consumers' behaviors and purchasing patterns. If done effectively, marketing segmentation allows an organization to achieve its highest return on investment (ROI) in turn for its marketing and sales expenses. If an organization markets its products or services to a consumer or business, it should focus on the various types of segmentation. Kotler (2010) describes segmentation as the classification of consumers within a market that share related needs and establish related purchasing behavioral habits.
\end{abstract}

Keywords: market segmentation; customer classification; marketing

\section{INTRODUCTION}

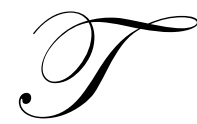

he world is made up of many different consumers, each with their own set of needs and behaviors. Segmentation seeks to complement consumers with products that satisfy their individual set of needs and behavior patterns. As a result, this is known as a 'segmenting'. Think of a market as a chain of connected and unique segments, each with its own profile. Companies can uncover new segments by researching the hierarchy of attributes that consumers will consider when choosing a brand (Kotler).

Marketing segmentation strategies can be cultivated through an extensive choice of attributes found among purchasers. One faction within the market may be recognized by gender, while another may be made up of purchasers within a certain age category. Locality is another general element in market segmentation, along with earning level and culture level. Therefore, although this causes some consumers who fall into more than one class, marketing researchers generally allow for this singularity. As a function of the development of a particular set within the larger consumer base, some businesses are forced to ask questions that start some realistic suggestions on how to make a product or service more advantageous to consumers. This action may point to additional comparable changes that do not affect the main product or service. Nevertheless, creating a few changes in the growth of a product or service sends a transparent communication message to customers that the organization does pay attention to purchasers.

\section{Marketer Responsibilities}

Organizations should know their current and future marketing size. According to Kotler \& Armstrong (1996), a market is a set of products or services, a market is a group of buyers, and in an industry, a group of sellers that they serve. The most important task of an organization in marketing is to measure their current market demand, which can be viewed in terms of total region or local market demand (Kotler \& Armstrong). Total market demand is not a fixed number, but a function of the marketing environment as well as the level and mix of industry marketing (Kotler \& Armstrong). An organization must know what their competitor is doing; they should notice trends and respond to them. Marketing is an extensive field that incorporates areas of research, tactics and exchange of ideas. Marketing plays a significant role for numerous organizations and improves value for the consumers and develops consumer relationships. Because of the needs, preferences, and behaviors of segment, consumers are similar but not identical (Kotler, 2001). 


\section{The Reason For Segmenting Consumer Markets}

There is no single way to segment a market. A marketer has to try different segmentation variables, alone and in combination (Kotler \& Armstrong, 1996). In order to be successful in today's global market, Organizations will have the think innovatively, be willing to change and quickly adapt to the new ways of conducting business in this twenty-first century. Nevertheless, a great deal of organization is now facing a larger number of small consumers who do not think segmentation is worthwhile. However, these suppliers must look for broad classes of consumers who adapt in their products or services needs and buying habits (Kotler \& Armstrong). Previous studies show that mass marketing creates the largest potential market at the lowest costs, which can lead to lower prices and higher profit margins.

\section{Diversity In Marketing Segmentation}

Consumer diversity is growing quickly and organizations have prolonged how to make a distinction between their products and services and that of the competition. This is where marketing segmentation plays a key role. The United States will undergo a major transformation in its cultural and ethnic composition over the next 20 years. Economic factors will be the cause of these changes. Today's shrinking labor market is mostly comprised of low to middle class citizens. This creates a slower-responding consumer market than if it was made up of upper class workers. However, the organization that is willing to begin segmenting and targeting the right products and services to match all of today's diverse cultures will create a competitive edge over their competitors.

\section{CONSUMER MARKET SEGMENTATION}

Consumer market segmentation includes:
- $\quad$ Geographical
- Demographical
- Behavior
- $\quad$ Psychographic

\section{Geographical Segmentation For Consumers}

The geographic segmentation signifies a market divided by location. Geographic segmentation is based on the belief that consumers who live in the same region share some related wants and needs and those wants and needs could be very different from the consumers who are living in other regions of the world. For example, some products and services have high demand in one region but not demanded in other regions. Despite its meaning, geographic segmentation may differ from area to area. Geographic biases may depend on the different brands available. In a number of areas, one brand may be very well liked and accepted but it may not be known by a majority of the consumers.

\section{Demographical Segmentation}

Demographic segmentation consists of demographic factors such as age, ethnicity, nationality, occupation, etc. Therefore, with these variables in mind, an organization can choose which consumer they will accommodate. For example, an organization dealing with the younger generation will have to target the consumers between the ages of 18 and 45 years, while an organization dealing the older generation will have to concentrate on consumers between 46 and up. Demographic segmentation aids an organization in understanding its consumers and satisfying their wants and needs. In today's global market, competition is driven by a strong competition causing demographic marketing analysis to be a great advantage to any organization.

\section{Behavior Segmentation}

A variety of strategies for segmentation is available. However, previous studies show recommendations that behavior-based strategies work well for most organizations. Segmentation based on consumer behavior 
variables normally included a sub-segment of consumer segmentation. Organizations often collect this data to see the segment that best fits their consumer behavior. Behavioral segmentation can be the answer for a great deal of organizations on where to lavish their next marketing dollar.

\section{Psychographic Segmentation}

Psychographic segmentation was developed by marketing researchers to correlate personality with brands. Psychographics is classified as "the study of personality, values, attitudes, interests, and lifestyles." Organizations need to know their consumers' habits to effectively connect with them and for the consumer to identify the organization's products or services. Psychographic segmentation acts on the psychology of the prospective consumer and helps the merchant decide how he or she must manage their consumer that belongs to any specific segment.

\section{BUSINESS SEGMENTATION}

Business Segmentation includes:

- Geographical Segmentation

- $\quad$ Customer type

- $\quad$ Buyer Behavior

\section{Geographical Segmentation For Business}

Geographical segmentation is a marketing tactic in which prospective consumers are divided on the basis of geographic units, such as cities, states, countries, etc. The critical intent of any organization is to make a profit. To accomplish this goal, an ideal marketing tactic is necessary. Marketing is a broad concept, which entails various actions, like studying the buyer's behavior, needs and personal preferences. Promoting and selling any product and service using a variety of techniques is exceptionally important. It is also vital that marketers recognize the diversity of each consumer and identifies their needs by the different segments of markets.

\section{Customer Type}

Customer type segmentation is used when an $\mathrm{n}$ organization need to influence a certain consumer type. Instead of offering a services or products to everyone, organizations tailor each product and marketing tactic to a specific target markets. By using customer type segmentation, companies are able to effectively allocate marketing resources by targeting only the populations who are most likely to buy what they are selling.

\section{Buyer Behavior}

Buyer behavior is the study of how consumers purchase. Nonetheless, before an organization can start to shape their consumers behavior, they must establish which market segment they will be concentrating on. One of the most important factors in marketing is segmentation. Knowledge is developed due to buyer behavior analysis and it is extremely advantageous when developing market positions, customer commitment, and pricing plans. Consumers will make extra effort and become more engaged in their purchase if it is important to them, especially if they have no prior knowledge of buying that particular product or service.

\section{CONCLUSION AND RECOMMENDATIONS}

There are number of ways in which a market can be segmented. An organization will need to use the right strategy that is best for it products or services. Often, the best choice arises from using various strategies. The perception of cultural differences in today's global market could be the key for any organization's success. As a result, every organization will need to shape their marketing strategies to their consumer's buying habits. 


\section{AUTHOR AUTOBIOGRAPHY}

Gillian Coote Martin. I live in South Florida and am married with 2 boys. Currently, I am a Marketing Instructor at Kaplan University. I am also the CEO \& Principal Consultant of Coote Consulting Group. I have a Bachelor of Science in Business Management and Marketing and Master of Management from the University of Phoenix. At present, I am in the DBA program with an emphasis in Marketing at Argosy University (Class of December 2011).

\section{REFERENCES}

1. Armstrong, G. \& Kotler, P. (2008) Principle of marketing. Prentice Hall

2. Kotler, K. (2001). A framework of marketing management. Prentice Hall 